Gökay Çakıroğlu

Bekir Şener

Abit Balın

http://dx.doi.org/10.21278/brod69401

\title{
APPLYING A FUZZY-AHP FOR THE SELECTION OF A SUITABLE TUGBOAT BASED ON PROPULSION SYSTEM TYPE
}

\author{
UDC 629.5.016: 629.5.017.3: 629.561.1
}

Professional paper

\begin{abstract}
Summary
Selection of a tugboat to be used in a port according to the operations to be carried out is a difficult problem that requires many criteria to be evaluated at the same time. This selection requires high experience as well as technical knowledge about tugboats and operations. In this study, a numerical analysis was carried out within the framework of design, operational and financial criteria to develop a method to select a tugboat. The propulsion/manoeuvring systems used in the tugboats were investigated and different criteria related to the tugboats with different propulsion systems were evaluated by subject matter experts through a survey including technical and financial data. The responses were interpreted with the fuzzy analytic hierarchy process to select a suitable tugboat alternative based on the type of propulsion system.
\end{abstract}

Key words: Tugboat; fuzzy analytic hierarchy process; propulsion system; manoeuvring

\section{Introduction}

The nature of transportation is directly influenced by international trends and global developments. Maritime economy has always an important place in world trade and transportation. Main arteries of maritime import-export economy are ports. In order to provide faster and safer traffic flow in the ports, besides good organization and coordination, it is necessary to have advanced suitable equipment and vessels that serve the respective port. Among them, tugboats enable faster and safer performance of manoeuvring in ports and consequently speed up the flow of goods through the port concerned.

A tugboat is a type of vessel that manoeuvres other vessels by pushing or pulling them either by direct contact or by means of a tow line [1]. Tugs typically move vessels that either are restricted in their ability to manoeuvre on their own such as ships in a crowded harbour or a narrow canal or those that cannot move by themselves such as barges, disabled ships, log rafts or oil platforms. Tugboats are powerful in terms of their size and strongly built, and some are ocean-going. A typical profile drawing of a tugboat is given in Fig. 1. 


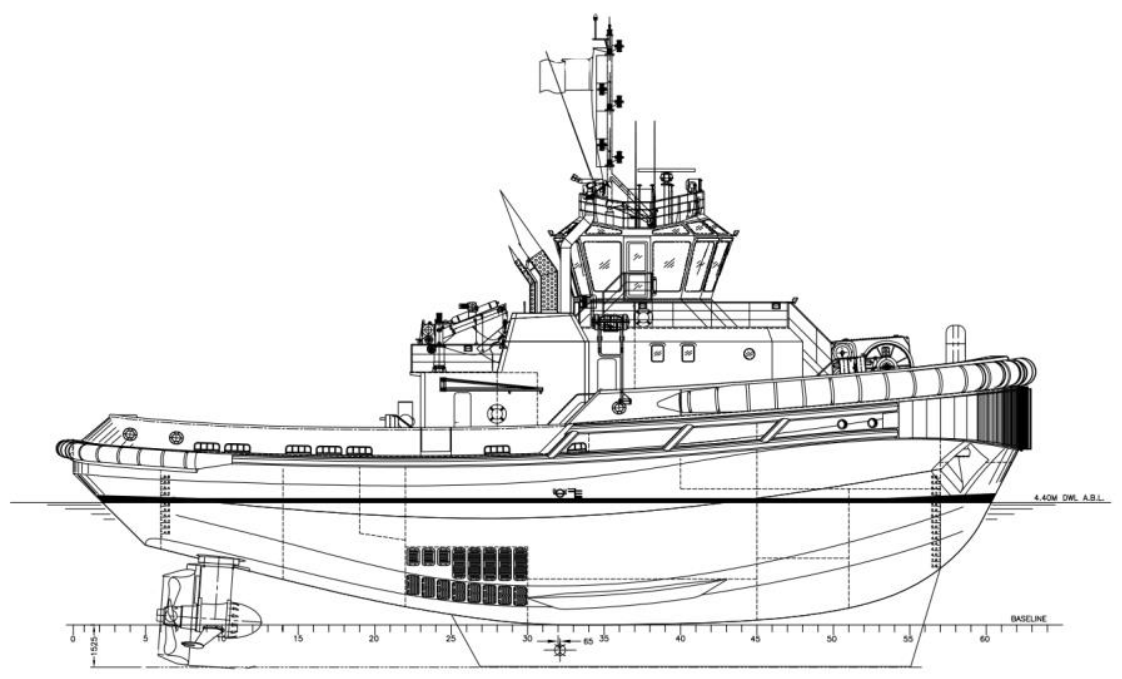

Fig. 1 A typical profile drawing of a tugboat (Credit: Sanmar Shipyard)

Tugboats are designed to perform one or more very specific functions. Of course, many tugboats also tend to get used to perform more than one of these duties and thus become more "multi-purpose". The primarily required specifications for tugboats are high manoeuvrability and power. However, it is important to understand that tugboats with different design features have different handling characteristics [2]. These could be, but not limited to, a combination of hull profile, engine and/or rudder type and thruster's configuration and towing winch design, power and location. Selection of the tugboats according to the port and operations to be used is of great importance in terms of efficiency and operating cost. Typically, tugboats are categorized according to the type of work they do, and then by the configuration or type of propulsion system used [3]. Main propulsion systems of the tugboats vary according to the operational requirements and capabilities of the tugboat. In general, there are three basic types of harbour tugboats according to the propulsion systems: Conventional, azimuth stern drive and tractor. The main differences between these 3 types are the equipment used in the propulsion system and the locations of these equipment. Details will be given in Table 5, third section $[4,5]$.

Numerous researches have been carried out related to the selection of propulsion and manoeuvring systems. The sophisticated techniques about the selection of waterjet propulsion systems for hydrofoil craft were examined by Hatte and Davis [6]. Barr, R. A. and Etter, R. J. [7] suggested a problem of matching ship performance and geometric requirements to propulsion system characteristics to select the best propulsion system for a specific application to be discussed. Stevens et al. [8] brought into question the superconducting electric propulsion machinery systems for a ship and examined $3000 \mathrm{hp}$ feasibility models of full scale systems. Unal et al. [9] discussed the Taguchi method for a propulsion system design optimization and proposed a systematic and efficient approach for transportation vehicle. Olcer and Odabasi [10] suggested a generalised fuzzy multiple attributive group decision making methodology about propulsion/manoeuvring system selection to warship requirements definition. Chang et al. [11] elaborated the safety requirements of dual-fuel gas turbine electric (DFGE) propulsion and dual-fuel diesel mechanical (DFDM) propulsion system. Castles et al. [12] assessed propulsion system inefficiency for destroyers and other marine vessels and proposed a hybrid drive operation system. The development of electric propulsion motors for naval and commercial ships was investigated by McCoy and Amy [13]. Mizythras et al. [14] advanced a new tool for simulation of a ship propulsion system performance during manoeuvring in shallow waters by coupling the propulsion system and seakeeping models. Martelli, M., and Figari, M. [15] examined the methodology and the 
simulation models required to design the propulsion control logics for an innovative combined diesel-electric and gas (CODLAG) propulsion plant. Altosole, M., and Martelli, M. [16] did propose a simulation based design methodology adopted to improve and check new control schemes for ship propulsion control strategies for emergency manoeuvres. Geertsma, et al. [17] put forward a propulsion model with a Mean Value First Principle (MVFP) diesel engine model that is likely to be parameterised with publicly available manufacturer data and further calibrated with obligatory Factory Acceptance Tests (FAT) and Sea Acceptance Tests (SAT) measurements. Geertsma et al. [18] presented a simulation model of a hybrid propulsion system to investigate two parallel control strategies for diesel mechanical and electrical propulsion on multifunction ships. Geertsma et al. [19] analysed the benefits and drawbacks, and trends in application of propulsion and power supply technologies, and they review the applicability and benefits of promising advanced control strategies. Mu et al. [20] assessed the podded propulsion unmanned surface vehicle model identification based on field experiments and verified by simulation data. Pugi et al. [21] proposed redundant and reconfigurable propulsion systems to improve motion capability of underwater vehicles and layout exhibit superior manoeuvring performances that are expected to be useful for the inspection of offshore plants and more generally for harsh operational conditions.

In this paper, a new multi-criteria decision making (MCDM) problem has been proposed in a fuzzy environment about ranking and selection of alternatives. A new methodology was presented with an application to the propulsion system selection problem. Thus, the research is devoted to find a useful and rational decision making model that enables to handle the already-mentioned problems. The main objective of this research is to make contribution to the development of an MCDM method with multiple decision makers, which are capable of working in a fuzzy environment. In spite of the fact that the method has already identified in some scientific articles for different areas, few studies are available for the importance ratings on propulsion system selection in the maritime industry.

This paper has been organized as follows: Section 2 is intended to outline the general concept of analytic hierarchy process problem, Section 3 propulsion system selection is used as a real case study to show the applicability of the proposed approach, and results of the evaluations and concluding remarks are presented in the last sections.

\section{Concept of analytic hierarchy process}

Proposed by Saaty [22, 23], Analytic Hierarchy Process (AHP) is traditionally a powerful decision-making methodology so as to determine the priorities among different criteria, enabling to compare alternatives for each criterion and to determine an overall ranking of the alternatives. It has also been used in various fields in the shipbuilding and maritime industry. Zamarin et al. [24] developed a novel three-stage methodology for selection of optimal mast and standing rigging using AHP in the first two stages and FEM analysis in the final stage. Balin et al. [25] implemented fuzzy AHP and VIKOR techniques to the expert failure detection of marine diesel engine and auxiliary systems. Kafali et al [26] used AHP to evaluate different pipe cutting methods used in shipyards in accordance with the criteria which consist of three main factors and fourteen sub-factors, and determined the most appropriate method. Stanic et al. [27] investigated modern production concepts to improve productivity and decrease operational costs in shipbuilding process. AHP was used after a three-phase methodology to select the optimal solution. Their methodology could also be used to detect the topics that need improvements and some other crucial points to overall reduction in costs.

The conventional AHP is hardly sufficient to handle the imprecise or vague nature of linguistic assessment. Possible to be represented by the triangular fuzzy numbers (TFNs) [28] 
in fuzzy AHP, common sense linguistic statements have been utilized in the pair-wise comparison. Then, the step of combining the pair-wise comparison and the synthesis of the priorities to decide on the overall priorities of the decision alternatives will be done [29].

The cause of TFNs being used to capture the vagueness of the linguistic assessments is that TFN is open to use both in intuitive and easy way. The TFNs in the pair-wise comparison are defined with the help of three real numbers expressed as a triple $(1, \mathrm{~m}, \mathrm{u})$. These values are defined on the basis of the smallest possible value, the most promising value, and the largest possible value that describes a fuzzy event. The one that looks to better match the preferences scale of the Fuzzy AHP is summarized in Table 1.

Table 1 Triangular fuzzy conversion scale

\begin{tabular}{|l|l|}
\hline Linguistic Scale & TFNs/ Reciprocal TFNs \\
\hline AS-Absolutely Strong & $(3.50,4.00,4.50)$ \\
\hline VS-Very strong & $(2.50,3.00,3.50)$ \\
\hline FS-Fairly Strong & $(1.50,2.00,2.50)$ \\
\hline SS-Slightly strong & $(0.50,1.00,1.50)$ \\
\hline E-Equal & $(1.00,1.00,1.00)$ \\
\hline SW-Slightly weak & $(0.67,1.00,2.00)$ \\
\hline FW-Fairly weak & $(0.40,0.50,0.67)$ \\
\hline VW-Very weak & $(0.29,0.33,0.40)$ \\
\hline AW-Absolutely weak & $(0.22,0.25,0.29)$ \\
\hline
\end{tabular}

The operations on TFNs can be addition, multiplication, and inverse. Suppose M1 and M2 are TFNs where $\mathrm{M}_{1}=\left(\mathrm{l}_{1}, \mathrm{~m}_{1}, \mathrm{u}_{1}\right)$ and $\mathrm{M}_{2}=\left(\mathrm{l}_{2}, \mathrm{~m}_{2}, \mathrm{u}_{2}\right)$; then,

Addition:

$$
\mathbf{M}_{1} \oplus \mathbf{M}_{2}=\left(\mathrm{l}_{1}+\mathrm{l}_{2}, \mathrm{~m}_{1}+\mathrm{m}_{2}, \mathrm{u}_{1}+\mathrm{u}_{2}\right)
$$

Multiplication:

$$
\begin{aligned}
& M_{1} \otimes M_{2}=\left(l_{1} \cdot l_{2}, m_{1} \cdot m_{2}, u_{1} \cdot u_{2}\right) \\
& M_{1}^{-1}=\left(l_{1}, m_{1}, u_{1}\right)^{-1} \cdot\left(1 / u_{1}, 1 / m_{1}, 1 / l_{1}\right)
\end{aligned}
$$

\section{Step 1: Construct the fuzzy pair-wise comparison matrix}

To construct the fuzzy judgment matrix $\tilde{A}=\tilde{a}_{i j}$ of $\mathrm{n}$, criteria or alternatives via pair-wise comparison by asking which is the more important of each two criteria, the TFNs are used as follows by equation (4).

$$
\tilde{A}=\left[\begin{array}{cccc}
1 & \tilde{a}_{12} & \ldots & \tilde{a}_{1 n} \\
\tilde{a}_{21} & 1 & \ldots & \tilde{a}_{2 n} \\
\ldots & \ldots & \ldots & \ldots \\
\tilde{a}_{n 1} & \tilde{a}_{n 2} & \ldots & 1
\end{array}\right]
$$

where $\tilde{a}_{i j}$ is a fuzzy triangular number, $\tilde{a}_{i j}=l_{i j}, m_{i j}, u_{i j}$, and $\tilde{a}_{j i}=1 / \tilde{a}_{i j}$. For each TFN, $\tilde{a}_{i j}$ or $\mathrm{M}=(l, m, u)$, its membership function $\mu_{\tilde{a}}(x)$ or $\mu_{M}(x)$ is a continuous mapping from real number $-\infty \leq x \leq \infty$ to the closed interval $[0,1]$ and can be defined by equation (5). 


$$
\mu_{\tilde{a}}(x)=\left\{\begin{array}{cc}
(x-l) /(m-l), & l \leq x \leq m \\
(u-x) /(u-m), & m \leq x \leq u \\
0 & , \text { otherwise }
\end{array}\right.
$$

\section{Step 2: Aggregate the group decisions}

Subsequent to the collection of the fuzzy judgment matrices from all decision makers, these matrices can be assembled by dint of the fuzzy geometric mean method (6) of Buckley [30, 31]. The total TFN of $n$ decision makers' judgment in a certain case $\tilde{u}_{i j}=\left(l_{i j}, m_{i j}, u_{i j}\right)$ is:

$$
\tilde{\mathrm{u}}_{\mathrm{ij}}=\left(\coprod_{i=1}^{n} \tilde{a}_{i j k}\right)^{1 / n}
$$

where $\tilde{a}_{i j k}$ is the relative importance in form of TFN of the $k_{t h}$ decision maker's view, and $\mathrm{n}$ is the total number of decision makers.

\section{Step 3: Compute the value of fuzzy synthetic extent:}

Based on the aggregated pair-wise comparison matrix, $\tilde{U}=\tilde{u}_{i j}$, the value of fuzzy synthetic extent $S_{i}$ with respect to the $i_{\text {th }}$ criterion can be computed as (7) by making use of the algebraic operations on TFNs as described in (1)-(3).

$$
W_{i}=\sum_{j=1}^{m} \tilde{\mathrm{u}}_{\mathrm{ij}} \otimes\left[\sum_{i=1}^{n} \sum_{j=1}^{m} \tilde{\mathrm{u}}_{\mathrm{ij}}\right]^{-1}
$$

where

$$
\sum_{j=1}^{m} \tilde{\mathrm{u}}_{\mathrm{ij}}=\left(\sum_{j=1}^{m} l_{\mathrm{j}}, \sum_{j=1}^{m} m_{\mathrm{j}}, \sum_{j=1}^{m} \mathrm{u}_{\mathrm{j}}\right) \text { and } \sum_{i=1}^{n} \sum_{j=1}^{m} \tilde{\mathrm{u}}_{\mathrm{ij}}=\left(\sum_{i=1}^{n} l_{\mathrm{j}}, \sum_{i=1}^{n} m_{\mathrm{j}}, \sum_{i=1}^{n} \mathrm{u}_{\mathrm{j}}\right)
$$

Step 4: Calculate best non-fuzzy performance (BNP) value

Utilize Center of Area (COA) method to find out the best non-fuzzy performance (BNP) value (crisp weights) of each criterion by the Equation (8).

$$
B N P \tilde{w}_{i}=\left[\left(u w_{i}-l w_{i}\right)+\left(m w_{i}-l w_{i}\right)\right] / 3+l w_{i}
$$

In accordance with the value of the derived BNP for each of the alternatives, the ranking of the each alternative can then proceed.

\section{Step 5: Consistency test of the comparison matrix}

To ensure a certain quality level of a decision, we are required to analyze the consistency of an evaluation. With the aim of testing the value of consistency of the comparison matrix depended on $n$, the consistency rate (CR) needs to be computed. The CR is described in (9) as a ration between the consistency of a consistency index (CI) and the consistency of a random consistency index (RI). Its value should not surpassed 0.1 for a matrix larger than $4 \times 4$. For pair-wise comparison matrix being compatible, upper-bound of CR should be as shown in Table $2[22,23]$.

$$
\mathrm{CR}=\mathrm{CI} / \mathrm{RI}
$$


Table 2 Upper bound for pair-wise comparison matrix to be compatible

\begin{tabular}{|l|l|l|l|}
\hline $\mathbf{n}$ & $\mathbf{3 x 3}$ & $\mathbf{4 x 4}$ & $\mathbf{n}>\mathbf{4}$ \\
\hline$C R \leq$ & 0.58 & 0.90 & 1.12 \\
\hline
\end{tabular}

The CI is used to measure the inconsistency pair-wise comparison as shown in (10) where the eigenvalue $\lambda \max$ can be computed by averaging all eigenvalues of the pair-wise comparison matrix (11). Table 3 shows values of RI in different values of $n$.

$$
\begin{aligned}
& \mathrm{CI}=\left(\lambda_{\max }-n\right) /(n-1) \\
& \lambda_{\max }=\sum_{j=1}^{n} a_{i j} \frac{W_{j}}{W_{i}}=n \quad i, j=1,2, \ldots, n
\end{aligned}
$$

Table 3 Values of random consistency index (RI) per different number of criteria [32]

\begin{tabular}{|l|l|l|l|}
\hline $\mathbf{n}$ & $\mathbf{R I}$ & $\mathbf{n}$ & $\mathbf{R I}$ \\
\hline 3 & 0.58 & 10 & 1.49 \\
\hline 4 & 0.90 & 11 & 1.51 \\
\hline 5 & 1.12 & 12 & 1.48 \\
\hline 6 & 1.24 & 13 & 1.56 \\
\hline 7 & 1.32 & 14 & 1.57 \\
\hline 8 & 1.41 & 15 & 1.59 \\
\hline 9 & 1.45 & & \\
\hline
\end{tabular}

\section{Case study: Selection of suitable tugboat according to propulsion system for ports of Turkey}

Selection of a suitable tugboat for a port is a very complex task that requires many criteria to be evaluated at the same time. In this study, it is aimed to apply fuzzy analytic hierarchy process to this selection problem. Fig. 2 displays hierarchical structure designed in compliance with Buckly's fuzzy AHP method that includes criteria and tugboat alternatives. Short definitions of the criteria that have effect on the selection of the tugboat are given in Table 4.

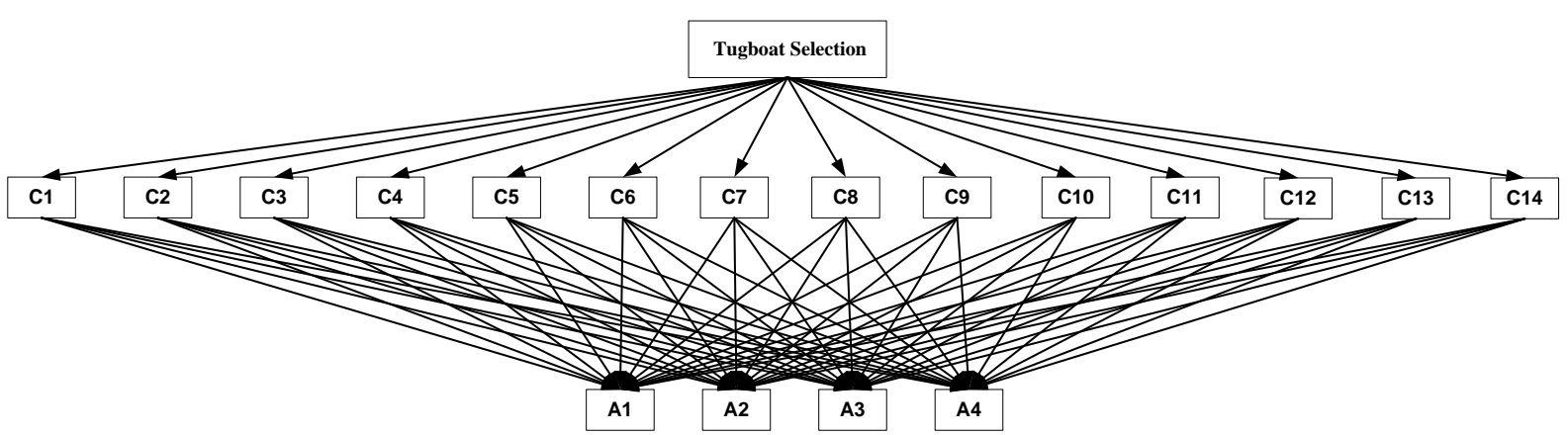

Fig. 2 Hierarchical structure for tugboat selection according to propulsion system type 
Table 4 Definitions of selected criteria and tugboat alternatives

\begin{tabular}{|l|l|l|}
\hline No & \multicolumn{1}{|c|}{ Criteria } & \multicolumn{1}{|c|}{ Definition } \\
\hline C1 & Bollard pull & $\begin{array}{l}\text { It is a conventional measure of the pulling (or towing) power of } \\
\text { a tugboat. It is defined as the force exerted by a tugboat under } \\
\text { full power and used for measuring the strength of tugboats. }\end{array}$ \\
\hline C2 & Speed & Maximum and/or service speed of a tugboat \\
\hline C3 & Tank capacity & Capacity of the fuel tank and the other tanks \\
\hline C4 & Seakeeping & $\begin{array}{l}\text { The seakeeping performance accounts for the performance of a } \\
\text { tugboat in wind, waves and current. The performance can be } \\
\text { expressed in terms of comfort, crew workability, damage to } \\
\text { ship and cargo due to ship motions. }\end{array}$ \\
\hline C5 & Deck arrangement & $\begin{array}{l}\text { The size of working area on deck and the arrangement of the } \\
\text { equipment e.g. winches, windlass, and hook }\end{array}$ \\
\hline C6 & Hull form & $\begin{array}{l}\text { The underwater design of the tugboat and the characteristic of } \\
\text { the hull lines }\end{array}$ \\
\hline C7 & Working environment & The environmental conditions in which the tugboat will work \\
\hline C8 & Safety & $\begin{array}{l}\text { Vessel stability in towing operation and critical equipment } \\
\text { installation on deck and engine room }\end{array}$ \\
\hline C9 & Maintenance & Short-time, easy and cheaper maintenance \\
\hline C10 & Operation & Low operation costs, e.g. low fuel consumption, low crew cost \\
\hline C11 & Functionality & $\begin{array}{l}\text { Easy line handling and best manoeuvring in limited areas at the } \\
\text { port }\end{array}$ \\
\hline C12 & Price & Required capital and operational expenses \\
\hline C13 & Delivery time & Short-term construction after order confirmation \\
\hline C14 & Maturity possibility & Support to the customer for financing issues \\
\hline
\end{tabular}

As mentioned in introduction section, tugboats are generally categorized according to the configuration or type of propulsion system used. In general, there are three basic types of harbour tugboats: Conventional, azimuth stern drive (ASD) and tractor. Tractor type tugboats are also divide into 2 main types. The main difference between these types is the equipment used in the propulsion system and the locations of these equipment. Short definitions and informative profile silhouettes of alternative tugboats used in study are given in Table 5. 
Table 5 Alternative tugboat types according to the propulsion system

\begin{tabular}{|c|c|c|c|}
\hline No & Alternative & Profile silhouette & Definition \\
\hline A1 & $\begin{array}{l}\text { ASD - Azimuth stern } \\
\text { drive tug }\end{array}$ & & $\begin{array}{l}\text { A tug fitted with two azimuth thrusters in } \\
\text { nozzles at the stern. }\end{array}$ \\
\hline A2 & Conventional tug & & $\begin{array}{l}\text { A tug fitted with fixed propellers, single } \\
\text { or twin screw (left or right handed) and } \\
\text { single rudders with fixed nozzles. }\end{array}$ \\
\hline A3 & ASD Tractor tug & & $\begin{array}{l}\text { A tug with azimuth thrusters located } \\
\text { generally forward off the midship and a } \\
\text { rudder-shaped fin at aft side. }\end{array}$ \\
\hline A4 & $\begin{array}{l}\text { VSP (Voith-Schneider } \\
\text { Propeller) Tractor tug }\end{array}$ & & $\begin{array}{l}\text { A tug with Voith-schneider propellers } \\
\text { generally located forward off the midship } \\
\text { and a rudder-shaped fin at aft side. }\end{array}$ \\
\hline
\end{tabular}

According to the hierarchical structure created, pairwise comparisons to the tugboats with different propulsion systems by subject-matter-experts have been employed for geometric average proposed by Buckley Fuzzy AHP. Triangular Fuzzy Numbers (TFN) in pairwise comparison have been utilized instead of real numbers so as to identify the triple (l, $\mathrm{m}, \mathrm{n})$ where $1 \leq \mathrm{m} \leq \mathrm{u}$ is.

\section{Results and discussion}

All views of subject-matter-experts have been evaluated as stated above. A common view has been obtained by taking the geometric average of all pairwise comparisons. This common view was evaluated by Buckley Fuzzy AHP and the results are shown in Table 6.

The results obtained according to the criteria by examining the solutions in detail are shown in Table 7. As shown, according to the evaluations of subject-matter-experts, it is obvious that criteria $\mathrm{C} 8(0.130)$ and $\mathrm{C} 1(0.118)$ affects the selection of tugboat type mostly. The C14, C5, C6, and C3 criteria are in the last place with (0.050), (0.052), (0.053), and (0.054), respectively. In this case, it can be seen that C8 and C1 criteria are the most important factors affecting the selection of the tugboat regarding the propulsion system. On the other hand, it has been observed that the C14, C5, C6 and C3 criteria less influence the selection of the tugboat than the other criteria. 
Table 6 Criteria-criteria pairwise comparison

\begin{tabular}{|c|c|c|c|c|c|c|c|c|c|c|c|c|c|c|}
\hline & C1 & C2 & C3 & $\mathrm{C} 4$ & C5 & C6 & C7 & C8 & C9 & C10 & C11 & $\mathrm{C12}$ & C13 & C14 \\
\hline \multirow{3}{*}{ C1 } & & & & & & & & & & & & & & \\
\hline & 1.00 & 39 & .37 & .49 & .45 & .50 & 0.70 & 1.00 & .56 & .49 & .70 & .80 & 0.49 & 0.44 \\
\hline & 1.00 & 49 & 46 & .68 & .61 & .64 & .16 & .28 & .84 & .59 & .16 & .10 & .62 & .54 \\
\hline \multirow{3}{*}{$\mathrm{C} 2$} & 2.04 & .00 & .61 & .74 & .65 & .60 & .76 & .40 & 0.60 & 83 & .63 & .76 & .72 & .47 \\
\hline & 2.55 & 1.00 & 64 & .00 & 87 & .76 & 1.00 & 2.05 & .76 & .00 & .87 & 1.08 & 0.92 & 0.61 \\
\hline & 3.06 & .00 & 69 & .43 & .40 & 92 & 1.18 & .62 & .92 & .27 & .08 & .39 & .32 & .77 \\
\hline \multirow{3}{*}{ C3 } & 2.18 & 1.44 & 1.00 & 0.92 & 0.85 & 0.67 & 0.91 & .23 & 0.82 & .82 & .85 & .79 & .80 & .53 \\
\hline & 2.70 & 55 & .00 & 15 & 15 & .00 & .25 & .55 & .15 & 15 & 32 & 1.25 & .15 & 0.76 \\
\hline & 3.22 & & & & & & & 86 & & & & .64 & .72 & .00 \\
\hline \multirow{3}{*}{ C4 } & 1.48 & 0.70 & 0.63 & 1.00 & 0.65 & 0.60 & 0.79 & 2.67 & .87 & 76 & .89 & .02 & .74 & .56 \\
\hline & 2.05 & 1.00 & .87 & 1.00 & .87 & .76 & 1.00 & 3.18 & 1.00 & 1.00 & 1.32 & 1.32 & .15 & 0.76 \\
\hline & 2.58 & & & & .40 & & & .68 & .08 & & 70 & 56 & 97 & 1.06 \\
\hline \multirow{3}{*}{ C5 } & 1.64 & .72 & .55 & .72 & 1.00 & 0.80 & 1.28 & 2.26 & 0.72 & 89 & 18 & 53 & 87 & .74 \\
\hline & 2.22 & 1.15 & .87 & 1.15 & .00 & 1.15 & .52 & 2.77 & 1.15 & 32 & 52 & 1.89 & 15 & 1.15 \\
\hline & 2.76 & & & & .00 & .72 & & .27 & 1.53 & .70 & 99 & 2.23 & .50 & 1.97 \\
\hline \multirow{3}{*}{ C6 } & 1.56 & & & & & & & .62 & & & & 28 & 74 & 98 \\
\hline & 2.00 & 1.32 & 1.00 & 1.32 & 0.87 & 1.00 & 1.35 & 2.00 & 1.15 & 1.15 & 1.64 & 1.64 & .15 & 1.15 \\
\hline & 2.38 & 1.66 & 48 & & 25 & 1.00 & & 2.43 & 1.41 & 1.30 & 13 & 2.05 & 1.56 & 1.33 \\
\hline \multirow{3}{*}{ C7 } & 0.86 & & & & & & & .15 & & & & 18 & 69 & .49 \\
\hline & 1.43 & .00 & & & .66 & 0.74 & 1.00 & 1.74 & 1.00 & 1.15 & 1.15 & 1.32 & 87 & 0.64 \\
\hline & 1.97 & 32 & & 27 & .78 & 0.90 & 1.00 & 2.29 & 1.64 & 1.72 & 1.30 & 1.44 & 1.17 & 0.86 \\
\hline \multirow{3}{*}{ C8 } & 0.78 & & & & & & & .00 & .36 & & 42 & 50 & 38 & 0.34 \\
\hline & 1.00 & & & & & & & 1.00 & 0.45 & & 49 & 0.61 & 49 & 0.44 \\
\hline & 1.52 & .71 & & & 44 & .62 & & 1.00 & 0.61 & 0.68 & .59 & 0.81 & .71 & 0.62 \\
\hline \multirow{3}{*}{ C9 } & 1.19 & & & & & & & 1.64 & 1.00 & .87 & .70 & 91 & 62 & 0.50 \\
\hline & 1.78 & & & & & & & 2.22 & & & & 25 & 87 & 0.66 \\
\hline & 2.33 & 1.66 & & & .40 & 1.22 & & 2.76 & 1.00 & 1.08 & 1.35 & 1.51 & 1.32 & 0.85 \\
\hline \multirow{3}{*}{ C10 } & 1.70 & .79 & & & .59 & 0.77 & & 1.48 & 0.92 & 1.00 & 0.70 & 1.05 & 0.62 & 0.63 \\
\hline & 2.05 & & & & & & & 2.05 & & & & 1.25 & 0.87 & 0.76 \\
\hline & 2.38 & .20 & & & .12 & 1.06 & & 2.58 & 1.15 & 1.00 & 1.35 & 1.39 & 1.32 & 0.94 \\
\hline \multirow{3}{*}{ C11 } & 0.86 & 92 & & & .50 & 0.47 & & 1.70 & 0.74 & 0.74 & 1.00 & 0.96 & 0.48 & 0.42 \\
\hline & 1.43 & & & & & & & 2.05 & 1.00 & 1.00 & 1.00 & 1.25 & 0.66 & 0.56 \\
\hline & 1.97 & & & & & & & 2.38 & 1.43 & & 1.00 & 1.60 & 0.86 & 0.70 \\
\hline \multirow{3}{*}{$\mathrm{C} 12$} & 0.91 & 0.72 & 0.61 & 0.64 & 0.45 & 0.49 & 0.69 & 1.23 & 0.66 & 0.72 & 0.62 & 1.00 & 0.54 & 0.48 \\
\hline & 1.25 & 0.92 & & & & & & 1.64 & 0.80 & 0.80 & 0.80 & 1.00 & 0.76 & 0.64 \\
\hline & 1.51 & & & & & 0.78 & & 2.01 & 1.10 & 0.96 & 1.04 & 1.00 & 1.29 & 1.05 \\
\hline \multirow{3}{*}{ C13 } & 1.61 & 0.76 & 0.58 & 0.51 & 0.67 & 0.64 & 0.85 & 1.40 & 0.76 & 0.76 & 1.16 & 0.78 & 1.00 & 0.85 \\
\hline & 2.05 & 1.08 & & & & & 1.15 & 2.05 & 1.15 & 1.15 & 1.52 & 1.32 & 1.00 & 1.00 \\
\hline & 2.42 & 1.39 & & & & 1.35 & 1.44 & 2.62 & 1.62 & 1.62 & 2.06 & 1.84 & 1.00 & 1.32 \\
\hline \multirow{3}{*}{$\mathrm{C} 14$} & 1.85 & 1.30 & 1.00 & 0.94 & 0.51 & 0.75 & 1.16 & 1.61 & 1.18 & 1.06 & 1.42 & 0.95 & 0.76 & 1.00 \\
\hline & 2.30 & 1.64 & 1.32 & 1.32 & 0.87 & 0.87 & 1.55 & 2.30 & 1.52 & 1.32 & 1.78 & 1.55 & 1.00 & 1.00 \\
\hline & 2.67 & 2.13 & 1.90 & 1.80 & 1.35 & 1.02 & 2.06 & 2.90 & 1.99 & 1.60 & 2.36 & 2.11 & 1.18 & 1.00 \\
\hline
\end{tabular}


According to the evaluations of subject-matter-experts, as a result of pairwise comparisons, the most effective criteria on selection of tugboat according to the type of propulsion system is safety with a value of $0.130 \mathrm{BNP}$. Then, bollard pull with $0.118 \mathrm{BNP}$ value, price with $0.081 \mathrm{BNP}$ value, functionality with $0.074 \mathrm{BNP}$ value, speed with 0.069 $\mathrm{BNP}$ value, working environment with $0.069 \mathrm{BNP}$ value, operation with $0.065 \mathrm{BNP}$ value, maintenance with $0.064 \mathrm{BNP}$ value, seakeeping with $0.061 \mathrm{BNP}$, delivery time with 0.060 $\mathrm{BNP}$ value, tank capacity with $0.054 \mathrm{BNP}$ value, hull form with $0.053 \mathrm{BNP}$ value, deck arrangement with $0.052 \mathrm{BNP}$ value and maturity possibility with $0.050 \mathrm{BNP}$ value are listed, respectively. Concisely, in this case, it can be seen that $\mathrm{C} 8$ and $\mathrm{C} 1$ criteria are the most effective factors in the selection of the Tugboat according to the propulsion system. On the other hand, it has been observed that the C14, C5, C6 and C3 criteria less influence on the selection of the tugboat than the other criteria.

Table 7 Criteria evaluation solution results

\begin{tabular}{|l|cc|c|}
\hline & \multicolumn{3}{|c|}{$\begin{array}{c}\text { Weight } \\
\text { BNP- Best nonfuzzy } \\
\text { performance }\end{array}$} \\
\hline C1 & $\left(\begin{array}{lll}0.117 & 0.120 & 0.116\end{array}\right)$ & $(0.118)$ \\
\hline C2 & $\left(\begin{array}{lll}0.071 & 0.069 & 0.068\end{array}\right)$ & $(0.069)$ \\
\hline C3 & $\left(\begin{array}{lll}0.054 & 0.053 & 0.055\end{array}\right)$ & $(0.054)$ \\
\hline C4 & $\left(\begin{array}{lll}0.062 & 0.060 & 0.062\end{array}\right)$ & $(0.061)$ \\
\hline C5 & $\left(\begin{array}{lll}0.050 & 0.050 & 0.054\end{array}\right)$ & $(0.052)$ \\
\hline C6 & $\left(\begin{array}{lll}0.054 & 0.053 & 0.052\end{array}\right)$ & $(0.053)$ \\
\hline C7 & $\left(\begin{array}{lll}0.069 & 0.068 & 0.068\end{array}\right)$ & $(0.069)$ \\
\hline C8 & $\left(\begin{array}{lll}0.131 & 0.133 & 0.126\end{array}\right)$ & $(0.130)$ \\
\hline C9 & $\left(\begin{array}{lll}0.064 & 0.064 & 0.065\end{array}\right)$ & $(0.064)$ \\
\hline C10 & $\left(\begin{array}{lll}0.067 & 0.066 & 0.064\end{array}\right)$ & $(0.065)$ \\
\hline C11 & $\left(\begin{array}{llll}0.073 & 0.074 & 0.075\end{array}\right)$ & $(0.074)$ \\
\hline C12 & $\left(\begin{array}{lll}0.081 & 0.082 & 0.08\end{array}\right)$ & $(0.081)$ \\
\hline C13 & $\left(\begin{array}{llll|}0.057 & 0.059 & 0.064\end{array}\right)$ & $(0.060)$ \\
\hline C14 & $\left(\begin{array}{llll}0.050 & 0.049 & 0.051\end{array}\right)$ & $(0.050)$ \\
\hline
\end{tabular}

As shown in Table 8, among the alternative tugboat types, A1: ASD Type has been identified as the most suitable alternative with 7.255 BNP value and A4: Voith Tractor Type as the most unsuitable with 7.069 BNP value as a common opinion of all experts. The other alternatives were prioritized as Conventional Type as the second preferred alternative with 7.094 BNP value and ASD Tractor as the third preferred alternative with 7.075 BNP value.

Table 8 BNP values according to fuzzy AHP Method

\begin{tabular}{|l|c|}
\hline Alternative & BNP \\
\hline A1: ASD type propulsion system & 7.255 \\
\hline A2: Conventional type propulsion system & 7.094 \\
\hline A3: ASD Tractor type propulsion system & 7.075 \\
\hline A4: Voith Tractor type propulsion system & 7.069 \\
\hline
\end{tabular}


It should be noted that, although A1 should have been clearly distinguished from others, BNP values which indicate the order of the selection for other 3 alternatives are very close to each other. In other words, in this case, although determining the best alternative is easy with the BNP value, it is hard to determine the worst, or the last due to the fact that the BNP values of other three alternatives are very close to each other.

\section{Conclusion}

In this study, Fuzzy AHP methods, type of multi criteria decision making methods, have been applied to determine suitable tugboat according to the type of propulsion system. For this purpose, four alternative tugboat types were considered according to the fourteen criteria by taking into account subject-matter-experts opinions. Created decision models were modelled and evaluated by the technical experts of tugboat operators serving at Turkish ports, the engineers of international tugboat design firms and the expert academicians.

The fuzzy AHP model generated using the obtained data was analysed and the ranking among alternatives and criteria was given. According to the fuzzy AHP method results and expert opinions, it can be seen that $\mathrm{C} 8$ and $\mathrm{C} 1$ criteria are the most important factors affecting the selection of the tugboat type according to the propulsion system based on BNP values. Besides, C14, C5, C6 and C3 criteria have less effect on the selection than the other criteria.

Considering the impact of weight ratings, $\mathrm{C} 8$ and $\mathrm{C} 1$ criteria are the most effective factors and C14, C5, C6 and C3 criteria have less influence on the selection of the alternatives, A1: ASD Type has been determined as the most appropriate alternative with the 7.555 BNP value as the common opinion of all subject-matter-experts. The A4: Voith Tractor Type has been selected as the last choice to be preferred with the $7.069 \mathrm{BNP}$ value among four selected alternatives. It should be taken into account that the results of these assessments may vary if the weight of the criteria or the expert changes.

In the future studies, it is possible to develop a new method by changing or increasing / decreasing the criteria used in the evaluations. These methods will help companies that operate in national and international ports decide the type of tugboat they will invest. Similar applications can also be developed for different ship types.

\section{REFERENCES}

[1] Das, B., and Tejpal, N., 2008, "Major Factors Affecting Tugboat Ship Design and Construction,” Journal of Ship Production, 24(4), pp. 214-220.

[2] Das, B., and Tejpal, N., 2008, “A Computer Simulation Approach to Improving Tugboat Shipbuilding Design and Development Productivity,” Journal of Ship Production, 24(4), pp. 221-227.

[3] Radišić, Z., 2003, "Principal Types and Characteristics of Harbour Tugs," PROMETTraffic\&Transportation, 15(6), pp. 381-386.

[4] Eke, A. B., 2010, "Bollard Pull Calculations Related to Tug Management Implementation Methods," M.sc. Thesis, Institute of Science and Technology, Istanbul, http://hdl.handle.net/11527/9046

[5] Liu, Z. X., and Wang, S. M., 2004, "The Computer Simulation Study of Port Tugboat Operation,” J. Acta Simulata Systematica Sinica, 1, 014.

[6] Hatte, R., and Davis, H. J., 1967, "Selection of Hydrofoil Waterjet Propulsion Systems.” J. Hydronautics, $1-1$.

[7] Barr, R. A., and Etter, R. J., 1974, "Selection of Propulsion Systems for High Speed Advanced Marine Vehicles," Proc. Advanced Marine Vehicles Conference, Paper\#74-334, San Diego, California.

[8] Stevens, H., Superczynski, M., Doyle, T., Harrison, J., and Messinger, H., 1977, "Superconducting Machinery for Naval Ship Propulsion," IEEE Transactions on Magnetics, 13(1), pp. 269-274. https://doi.org/10.1109/TMAG.1977.1059460

[9] Unal, R., Stanley, D. O., and Joyner, C. R., 1993, "Propulsion System Design Optimization using the Taguchi Method," IEEE Transactions on Engineering Management, 40(3), pp. 315-322. https://doi.org/10.1109/17.233194 
Gökay Çakıroğlu, Bekir Şener Abit Balın
Applying fuzzy analytic hierarchy process to selection of suitable tugboat according to propulsion/manoeuvring system type for ports in Turkey

[10] Ölçer, A. I., and Odabaşi, A. Y., 2005, “A New Fuzzy Multiple Attributive Group Decision Making Methodology and its Application to Propulsion/Maneuvering System Selection Problem," European Journal of Operational Research, 166(1), pp. 93-114. https://doi.org/10.1016/j.ejor.2004.02.010

[11] Chang, D., Rhee, T., Nam, K., Chang, K., Lee, D., and Jeong, S., 2008, "A Study on Availability and Safety of New Propulsion Systems for LNG Carriers," Reliability Engineering \& System Safety, 93(12), pp. 1877-1885. https://doi.org/10.1016/j.ress.2008.03.013

[12] Castles, G., Reed, G., Bendre, A., and Pitsch, R., 2009, "Economic Benefits of Hybrid Drive Propulsion for Naval Ships," Proc. Electric Ship Technologies Symposium, pp. 515-520. https://doi.org/10.1109/ESTS.2009.4906560

[13] McCoy, T. J., and Amy, J. V., 2009, “The State-Of-The-Art of Integrated Electric Power and Propulsion Systems and Technologies on Ships," Proc. Electric Ship Technologies Symposium, pp. 340-344. https://doi.org/10.1109/ESTS.2009.4906534

[14] Mizythras, Panagiotis, Pollalis, C., Boulougouris, E., and Theotokatos, G., 2017, "Simulation of a Ship Propulsion System Performance During Manoeuvring in Shallow Waters," The 27th International Ocean and Polar Engineering Conference, International Society of Offshore and Polar Engineers.

[15] Martelli, M., and Figari, M., 2017, "Real-Time Model-based Design for CODLAG Propulsion Control Strategies," Ocean Engineering, 141, pp. 265-276. https://doi.org/10.1016/j.oceaneng.2017.06.029

[16] Altosole, M., and Martelli, M., 2017, "Propulsion Control Strategies for Ship Emergency Manoeuvres," Ocean Engineering, 137, pp. 99-109. https://doi.org/10.1016/j.oceaneng.2017.03.053

[17] Geertsma, R. D., Negenborn, R. R., Visser, K., Loonstijn, M. A., and Hopman, J. J., 2017, "Pitch Control for Ships with Diesel Mechanical and Hybrid Propulsion: Modelling, Validation and Performance Quantification,” Applied Energy, 206, pp. 1609-1631. https://doi.org/10.1016/j.apenergy.2017.09.103

[18] Geertsma, R. D., Negenborn, R. R., Visser, K., and Hopman, J. J., 2017, "Parallel Control for Hybrid Propulsion of Multifunction Ships," IFAC-PapersOnLine, 50(1), pp. 2296-2303. https://doi.org/10.1016/j.ifacol.2017.08.229

[19] Geertsma, R. D., Negenborn, R. R., Visser, K., and Hopman, J. J., 2017, "Design and Control of Hybrid Power and Propulsion Systems for Smart Ships: A Review of Developments," Applied Energy, 194, pp. 30-54. https://doi.org/10.1016/j.apenergy.2017.02.060

[20] Mu, D., Wang, G., Fan, Y., and Bai, Y., 2017, "Podded Propulsion Unmanned Surface Vehicle Model Identification Based on Field Experiments," Proc. 36th Control Conference, pp. 1995-1999. https://doi.org/10.23919/ChiCC.2017.8027646

[21] Pugi, L., Allotta, B., and Pagliai, M., 2018, "Redundant and Reconfigurable Propulsion Systems to Improve Motion Capability of Underwater Vehicles," Ocean Engineering, 148, pp. 376-385. https://doi.org/10.1016/j.oceaneng.2017.11.039

[22] Saaty, T. L., 1980, "The Analytic Hierarchy Process," Planning, Priority Setting, Resource Allocation, New York: McGraw-Hill.

[23] Saaty, T. L., 1994, "How to Make a Decision: The Analytic Hierarchy Process," Interfaces, Vol. 24, 6, pp. 19-43. https://doi.org/10.1287/inte.24.6.19

[24] Zamarin, A., Matulja, T., and Hadjina, M., 2013, "Methodology for Optimal Mast and Standing Rigging Selection of a Racing Yacht using AHP and FEM," Brodogradnja,, 64(1), pp. 11-21.

[25] Balin, A., Demirel, H., and Alarcin, F., 2015, "A Hierarchical Structure for Ship Diesel Engine Troubleshooting Problem using Fuzzy AHP and fuzzy VIKOR Hybrid Methods,” Brodogradnja, 66(1), pp. 5465.

[26] Kafali, M., Ozkok, M., and Cebi, S., 2014, "Evaluation of Pipe Cutting Technologies in Shipbuilding. Brodogradnja, 65(2), pp. 33-48.

[27] Stanić, V., Fafandjel, N., and Matulja, T., 2017, “A Methodology for Improving Productivity of the Existing Shipbuilding Process using Modern Production Concepts and the AHP Method," Brodogradnja, 68(3), pp. 37-56. https://doi.org/10.21278/brod68303

[28] Erensal, Y. C., Öncan, T., and Demircan, M. L., 2006, "Determining Key Capabilities in Technology Management using Fuzzy Analytic Hierarchy Process: A Case Study of Turkey," Information Science, Vol. 176, 18, pp. 2755-2770. https://doi.org/10.1016/j.ins.2005.11.004

[29] Srichetta, P., and Thurachon, W., 2012, "Applying Fuzzy Analytic Hierarchy Process to Evaluate and Select Product of Notebook Computers," International Journal of Modeling and Optimization, 2(2), 168. https://doi.org/10.7763/IJMO.2012.V2.105

[30] Buckley, J. J., 1985, "Ranking Alternatives using Fuzzy Numbers," Fuzzy Sets and Systems, Vol. 15, 1, pp. 21-31. https://doi.org/10.1016/0165-0114(85)90013-2

[31] Buckley, J. J., 1985, "Fuzzy Hierarchical Analysis," Fuzzy Sets and Systems, Vol. 17, 3, pp. $233-247$. https://doi.org/10.1016/0165-0114(85)90090-9 
[32] Yavuz, M., 2015, "Equipment Selection based on the AHP and Yager's Method," Journal of the Southern African Institute of Mining and Metallurgy, 115(5), pp. 425-433. https://doi.org/10.17159/24119717/2015/v115n5a10

Submitted: $\quad$ 06.03.2018. Gökay Çakıroğlu, gokaycakiroglu@yahoo.com

SANMAR Shipyard, 34947 Tuzla, Istanbul, Turkey.

Accepted: $\quad 31.08 .2018 . \quad$ Bekir Şener (*corresponding author), bsener@yildiz.edu.tr

Yildiz Technical University, Naval Architecture and Maritime Faculty,

34349 , Besiktas, Istanbul, Turkey.

Phone: +90 212 3832852, Fax: +90 2123833021

Abit Balın, abitbalin@istanbul.edu.tr

Istanbul University, School of Transportation and Logistics, 34320, Avcılar, Istanbul, Turkey. 